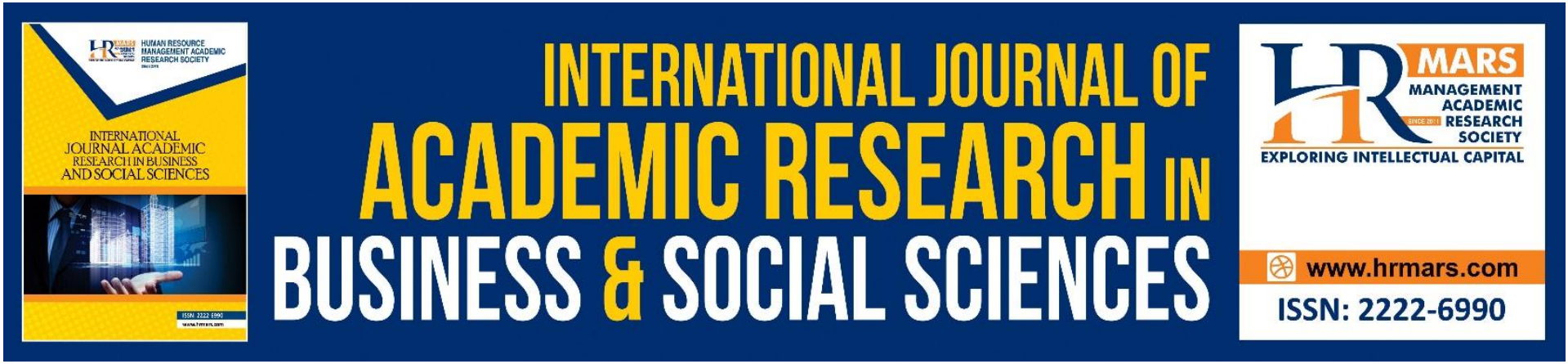

\title{
Technology Innovations toward Sustainable Growth of Small Medium Enterprise (SMEs): Aftermath COVID-19 Pandemic
}

\author{
Mohd Herry Bahador, Siti Sara Ibrahim
}

To Link this Article: http://dx.doi.org/10.6007/IJARBSS/v11-i2/9199

DOI:10.6007/IJARBSS/v11-i2/9199

Received: 07 December 2020, Revised: 09 January 2021, Accepted: 05 February 2021

Published Online: 26 February 2021

In-Text Citation: (Bahador \& Ibrahim, 2021)

To Cite this Article: Bahador, M. H., \& Ibrahim, S. S. (2021). Technology Innovations toward Sustainable Growth of Small Medium Enterprise (SMEs): Aftermath COVID-19 Pandemic. International Journal of Academic Research in Business and Social Sciences, 11(2), 1234-1241.

Copyright: (c) 2021 The Author(s)

Published by Human Resource Management Academic Research Society (www.hrmars.com)

This article is published under the Creative Commons Attribution (CC BY 4.0) license. Anyone may reproduce, distribute, translate and create derivative works of this article (for both commercial and non-commercial purposes), subject to full attribution to the original publication and authors. The full terms of this license may be seen at: http://creativecommons.org/licences/by/4.0/legalcode

Vol. 11, No. 2, 2021, Pg. 1234 - 1241

Full Terms \& Conditions of access and use can be found at http://hrmars.com/index.php/pages/detail/publication-ethics 


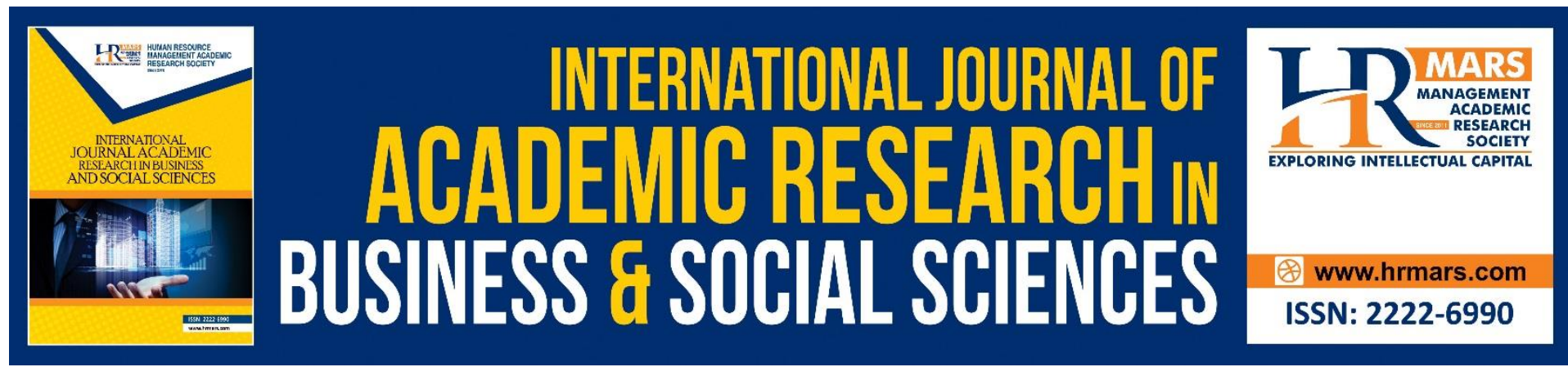

\title{
Technology Innovations toward Sustainable Growth of Small Medium Enterprise (SMEs): Aftermath COVID-19 Pandemic
}

\author{
Mohd Herry Bahador, Siti Sara Ibrahim \\ Universiti Teknologi PETRONAS (UTP), Universiti Teknologi MARA, Cawangan Negeri \\ Sembilan, Kampus Rembau, Malaysia
}

\begin{abstract}
Small and medium enterprises (SMEs) are vital to the economic growth of developing nations, due to the major segment of commercial activities that are conducted by such SMEs. However, the spread of the COVID-19 pandemic has severely affected supply and demand for SMEs as a result of worldwide lockdowns and restriction policies implemented in the effort to cull the outbreak of the virus. These restrictions, including the temporary closure of physical businesses and limited travel, have significant consequences towards sustainability in the growth of SMEs. SMEs must contend with challenges including decreased commercial opportunities, interruptions in the supply chain and human resources issues. In the face of these barriers, the evolution of the existing business models by adopting technology innovation can assist SMEs in establishing novel strategies to lay a foundation for future sustainable growth. Thus, the current study proposes a conceptual framework for a new business model which adopts technology innovation tools, namely the internet and web, big data analysis and artificial intelligence (Al). All these tools are adopted in alignment with the Technology Acceptance Model (TAM). This framework is vital in raising awareness regarding the role of technology innovation in rejuvenating the business operations of SMEs in order to ensure sustainable growth and survival in the wake of the COVID-19 pandemic.
\end{abstract}

Keywords: Technology Innovation, TAM Model, Sustainable Growth, COVID-19 Pandemic, SMEs.

\section{Introduction}

Small Medium Enterprises (SMEs) are growing to become vital players in the growth and evolution of economies in both developing nations as well transitional and developed marketcentric countries. SMEs continue to show increasing contributions to import and export, employment, overall GDP, and total establishment of new enterprises annually, reflecting the considerable influence of SMEs in economic development and recovery. To this end, policy makers have identified and given recognition to the significant function of SMEs in increasing innovation, competitiveness and employment in the economy, and how these capabilities help guarantee extensive and sustainable economic development.

The COVID-19 pandemic has sparked tremendous pressure for SMEs in their efforts to endure new challenges brought on by the outbreak (Papadopoulos, Baltas \& Balta, 2020). Global 
policies and strategies to tackle the COVID-19 outbreak are typically in the form of various limitations, including national lockdowns, quarantines, and the short-term cessation of physical business operations. Such restrictions carry consequences towards the operations and sustained growth of SMEs, resulting from the decreased business opportunities, supply chain disturbances and problems with retaining or hiring staff. The COVID-19 pandemic has triggered severe shifts in the business environment which has forced firms to adapt to extensively digital platforms and cope with stricter time pressures (Priyono, Moin \& Putri, 2020).

These problems require a long-term solution. Digital technology offers organizations the opportunity to evolve into other business models efficiently and creatively (Warner \& Wager, 2019). Literature points to the alteration of business models with the facilitation of digital technology as a method applied in response to dramatic environmental changes, especially technologies which assist the firm in identifying novel business decisions and practices (Richter, 2020). As such, digital technology tools are considered to be appropriate solutions to the challenges and changes brought on by the global consequences of the pandemic.

This study aims to propose a conceptual framework that illustrates the adoption of technology innovation among SMEs in a manner which contributes to their sustained growth and survival. This will consequently aid in the sustainability of the economy on a national scale. This study posits that the inclusion of technology innovation in busines operations of SMEs can assist those SMEs in efficiently responding to widespread crisis situations by applying various dynamic capacities (Vial 2019). In the wake of the COVID-19 outbreak, research has indicated that adapting to digital technology is vital in weathering the crisis, whether through utilizing the internet and websites, big data analysis, or artificial intelligence (Al) in the new model for business operations, which align with the Technology Acceptance Model (TAM).

\section{Literature Review}

\section{The Impact of COVID-19 Pandemic to SMEs Growth}

The novel coronavirus (COVID-19) originated in China, where 80,000 cases were recorded (Huang et al. 2020). The World Health Organization announced it as a pandemic and worldwide health crisis on 11 March 2020. The outbreak has since caused severe consequences for the global economy, including a state of widespread recession. The IMF World Economic Outlook, released on 24 June 2020, predicts a 4.9 percent deterioration in the worldwide GDP for this year, along with notable downward risk. The pandemic has resulted in major interruptions to business activities and forced many SMEs around the world to alter their current models of operation (Akpan, Soopramanien \& Kwak 2020). This state of a 'new normal' has prompted transformations in business operations, strategies, and behaviors. SMEs must identify and apply solutions to evolve along with the challenges that have emerged in this new environment (Syed 2019). The pandemic has given SMEs an avenue to tackle issues which have complicated the process of adopting new technologies. A major change that has already occurred is the transition to online business operations by SMEs around the world, as a response to consumer choices during global lockdowns and movement restriction orders.

\section{Technology Innovation: Internet and the Web}

Although the Internet has established a fresh landscape for Malaysian businesses for many years now, Small Medium Enterprises (SMEs) have not been as quick or comprehensive in 
adopting web technologies (Mansor, Halim \& Ahmad, 2018). SMEs anticipated various challenges involved in implementing IT tools into their business models, including the expenses, the potential risks, the complexity of processes, technical expatriation, and changes in customer service norms (Alam, 2009). The Internet has allowed for expansions in the infrastructure for digital communication, enabling contact between people and machines worldwide through universal interfaces and platforms (Aceto, Persico \& Pescape 2019). The development of wireless and ethernet networks has contributed to significant technology innovation in digital communications. The widespread accessibility of Wireless Local Area Network (WLAN) and personal mobile devices has also considerably decreased the effort and expense needed to ensure Internet connection to mobile devices (Wollschlaeger, Sauter, \& Jasperneite 2017; Ande et al. 2020).

Such developments have significantly impacted norms in technology and business and offer various advantages and avenues which include greater consumer value, predictive maintenance capacity, closed-loop design, and decreased cost of labor and new lines of service (McKnight 2017). However, it must be noted that without the Internet, many of these tools and programs would be compelled to function individually or not at all, resulting in major restrictions to the possibilities created by digital integration and communication.

\section{Technology Innovation: BIG Data Analysis}

Big data analytics is a tool which is applied to derive economic value from vast collections of various data through the use of high-velocity capture, discovery and subsequent analysis (Yang et al., 2017). Data obtained from social network platforms are the typical form of big data. Analysis of this data will support after-sales customer service which is innovative and tailored to the consumers, as well as reveal feedback related to improved marketing and design. There is increasing pressure to place emphasis on data mining and other business intelligences in order to maintain competitiveness in the global market and ensure the capacity to make swift decision-making processes in response to current data (Haddad, Ameen, \& Mukred, 2018). The utilization of big data along with visual and predictive analytics are vital in supporting major business choices in the context of the modern market (Akpan, Soopramanien, \& Kwak, 2020). Tools for high-speed cloud analytics and big data technology have considerably increased the relevance and precision of business analysis, allowing organizations to efficiently grasp opportunities within challenging environments (Briel et al. 2018).

\section{Technology Innovation: Artificial Intelligence}

Artificial Intelligence (Al) encompasses the capacity of a piece of technology to learn, reason and apply self-correction. Al functions on the basis of intelligent information and knowledge approaches (Li, Hou, Yu, Lu, \& Yang, 2017). Computer Vision, for example, is a vital system which improves technological outcomes by combining and facilitating various tools and techniques (Posada, 2020). Another relevant field is that of cyber-physical equivalence. This tool attempts to provide solutions towards the use of speedy 3D-capture technology to obtain information on moving items or articulated mechanical processes, and subsequently project this information in 3D form in a virtual context to enable more efficient task planning (Akpan \& Brooks 2012). These tools and others, which incorporate augmented and virtual realities, and digital twinning can be employed across many applications with the aim of obtaining data from sensors for the purpose of visualization and analysis (Dangelmaier et al. 2005; Akpan \& 
Shanker 2017). Harnessing such practices improves the designing and manufacturing process of the product as well the speed of its availability to the market.

\section{Actual System Use}

Actual system use refers to the physical user of a technological tool or system, and also measures the regularity of use of that tool. Davis (1989) explains this concept as external psychomotor responsiveness as reflected in the real-time frequency of use of a technology. The measurements incorporate both the frequency and period of time that the technology is put into use. Actual usage is indicated by the instances of frequent usage and repeated usage (Evwiekpaefe, Chiemeke \& Haruna, 2018). However, it is challenging to attempt to measure actual usage simply through a series of queries (Andarwati, Zuhroh, \& Amrullah, 2019). Literature has also proved that perceived usefulness is reliant on a range of forty-five relationships among dependent variables, which are actual usage behavior and intention to use (Li, Qi and Shu; 2008). Similarly, a direct relationship between behavioral intentions and the actual use of a tool or system must be taken into account (Venkatesh et al., 2003).

\section{Methodology}

This study conceptually reviews the possibilities of technology innovation through the lens of several independent variables, which are smart tools, the internet, artificial intelligence and big data, and how these elements contribute to the sustainable development of new SME entities. The comprehensive literature review in the previous section has been applied in the creation of a conceptual framework for this research, as proposed in the following section.

\section{Result and Findings}

Figure 1 below illustrates the proposed conceptual framework which explains the potential of adopting new technological innovations in efforts to support the growth of SMEs in the wake of the COVID-19 pandemic.

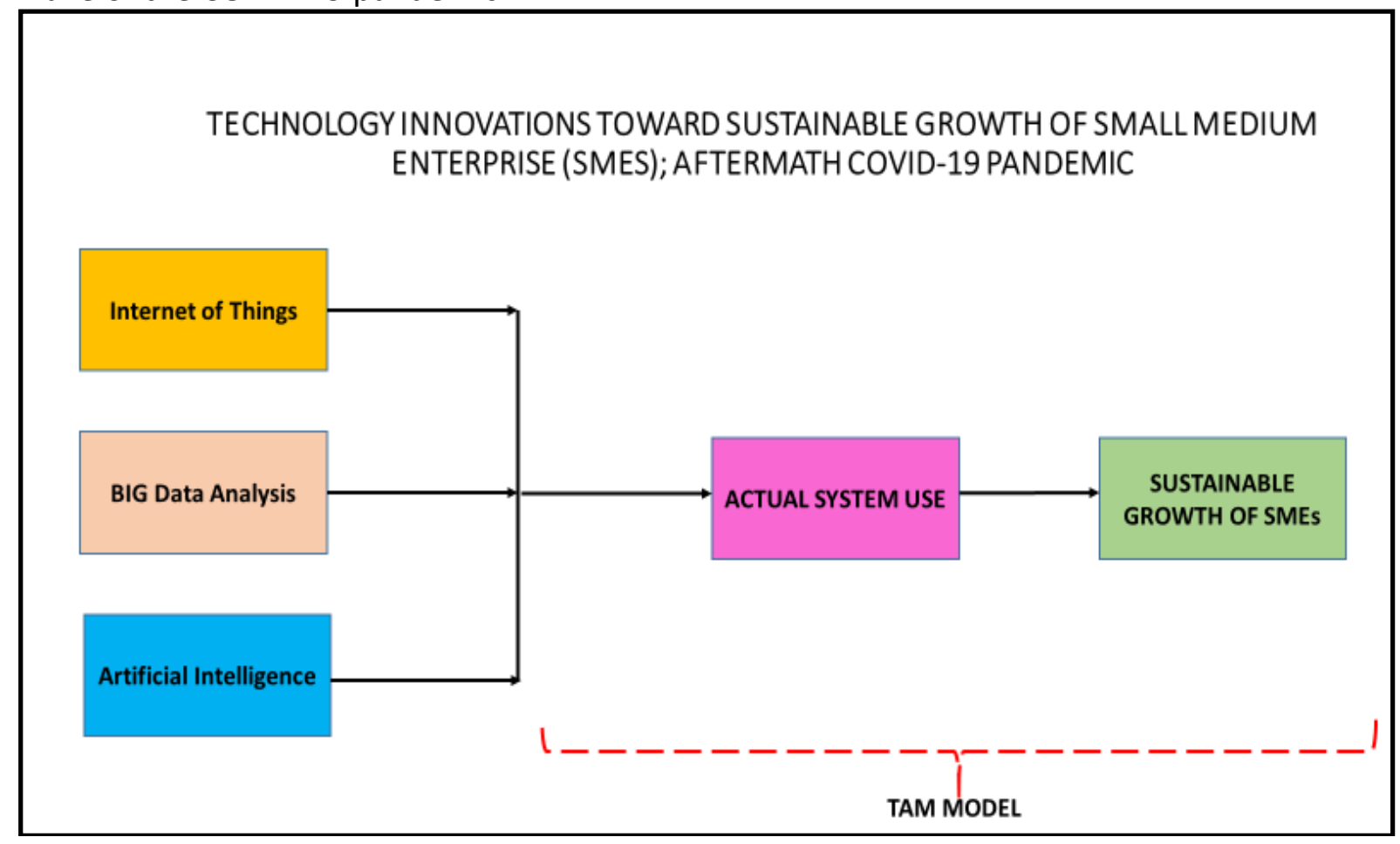

Figure 1. Proposed Conceptual Framework of the Study. 


\section{Conclusion}

The COVID-19 pandemic has wrought disastrous consequences on the global economy, jeopardizing the existence of small medium enterprises (SMEs) across the world. The outbreak has given rise to a highly challenging business environment for the continued sustainability of SMEs, and created circumstances leading to a global economic recession. In the wake of this pandemic, the adoption of digital technologies has provided a wealth of new and alternative avenues for business (Nambisan et al. 2019), particularly in fields including unmanned delivery services, online classes and online work. Digital technologies offer a decentralized quality which overcomes barriers of time and location, allowing for stronger engagement between firms and their fellow value creators and leading to better networking prospects (Zeng \& Glaister 2018). As such, the current study proposes the adoption of technology innovation in the business operations of new SMEs in order to guarantee sustainability in the growth of these enterprises in an environment impacted severely by the COVID-19 pandemic. Technology innovation tools include the internet, big data analysis and artificial intelligence systems which can be incorporated into the daily functions of SMEs. These types of digital technologies are able to be programmed, traced, communicated with, addressed, and integrated with other systems (Yoo 2010). In this way, the digitalization of business operations can support firms in establishing and maintaining competitive advantage through enhancements in organizational resilience and flexibility (Briel et al. 2018) and improvements in dynamic capacity (Sambamurthy et al. 2003; Vial, 2019). Organizations will be better equipped to handle challenges in the context of global crises with the support of digital technology tools.

\section{Acknowledgement}

We are grateful because we managed to complete our journal article of Technology Innovations toward Sustainable Growth of Small Medium Enterprise (SMEs): Aftermath COVID-19 Pandemic. We also sincerely thanks to those who involved directly or indirectly for the guidance and assistance in completing this journal article.

\section{Corresponding Author}

Siti Sara Ibrahim

Faculty of Business and Management, Universiti Teknologi MARA, Cawangan Negeri Sembilan, Kampus Rembau.

Email: saraibrahim@uitm.edu.my

\section{References}

\section{Journal articles}

Aceto, G., Persico, V., \& Pescape, A. (2019). A survey on information and communication technologies for Industry 4.0: state-of-the-art, taxonomies, perspectives, and challenges. IEEE Communications Surveys \& Tutorials, 21(4), 3467-3501.

Akpan, I. J., \& Brooks, R. J. (2012). Users' perceptions of the relative costs and benefits of 2D and 3D visual displays in discrete-event simulation. Simulation, 88(4), 464-480.

Akpan, I. J., \& Shanker, M. (2017). The confirmed realities and myths about the benefits and costs of 3D visualization and virtual reality in discrete event modelling and simulation: A descriptive meta-analysis of evidence from research and practice. Computers \& Industrial Engineering, 112, 197-211 
Akpan, I. J., Udoh, E. A. P., \& Adebisi, B. (2020). Small business awareness and adoption of state-of-the-art technologies in emerging and developing markets, and lessons from the COVID-19 pandemic. Journal of Small Business \& Entrepreneurship, 1-18.

Alam, S. S. (2009). Adoption of internet in Malaysian SMEs. Journal of Small Business and Enterprise Development.

Ande, R., Adebisi, B., Hammoudeh, M., \& Saleem, J. (2020). Internet of Things: Evolution and technologies from a security perspective. Sustainable Cities and Society, 54, 101728.

Andarwati, M., Zuhroh, D., \& Amrullah, F. (2019). End User Satisfaction of Accounting Information System (AIS) Mobile Based for Small Medium Enterprises (SMEs): Actual Usage and TAM Approach. Journal of Development Research, 3(2), 37-42.

Dangelmaier, W., Fischer, M., Gausemeier, J., Grafe, M., Matysczok, C., \& Mueck, B. (2005). Virtual and augmented reality support for discrete manufacturing system simulation. Computers in Industry, 56(4), 371-383.

Davis; Bagozzi, R. (1989). User Acceptance of Computer Technology: A Comparison of Two Theoretical Models. Management Science, 35(8), 982-1003.

Evwiekpaefe, A. E., Chiemeke, S. C., \& Haruna, M. Z. (2018). Individual and organizational acceptance of technology theories and models: Conceptual gap and possible solutions. Pacific Journal of Science and Technology, 10(2), 189-197.

Guo, H., Yang, Z., Huang, R., \& Guo, A. (2020). The digitalization and public crisis responses of small and medium enterprises: Implications from a COVID-19 survey. Frontiers of Business Research in China, 14(1), 1-25.

Haddad, A., Ameen, A., \& Mukred, M. (2018). The impact of intention of use on the success of big data adoption via organization readiness factor. International Journal of Management and Human Science (IJMHS), 2(1), 43-51.

Khan, D. S. (2017). Growth of Indian Economy through Innovative SME Financing Schemes-A Way Out. IOSR Journal of Business and Management (June 2017).

Li, B. H., Hou, B. C., Yu, W. T., Lu, X. B., \& Yang, C. W. (2017). Applications of artificial intelligence in intelligent manufacturing: a review. Frontiers of Information Technology \& Electronic Engineering, 18(1), 86-96.

Li, Y. Q., Qi, J. Y., \& Shu, H. Y. (2008). Review of relationships among variables in TAM. Tsinghua Science and Technology, 13 (3), 273-278.

Mansor, M. F., Halim, H. A., \& Ahmad, N. H. (2018). Leveraging crowdsourcing practices in small and medium enterprises (smes). Journal of Entrepreneurship Education, 21(4), 1-11.

McKnight, L. W., Etwaru, R., \& Yu, Y. (2017). Commodifying trust: Trusted commerce policy intersecting blockchain and internet of things.

Papadopoulos, T., Baltas, K. N., \& Balta, M. E. (2020). The use of digital technologies by small and medium enterprises during COVID-19: Implications for theory and practice. International Journal of Information Management, 55, 102192.

Posada, J. (2020). The Future of Work Is Here: Toward a Comprehensive Approach to Artificial Intelligence and Labour.

Priyono, A., Moin, A., \& Putri, V. N. A. O. (2020). Identifying Digital Transformation Paths in the Business Model of SMEs during the COVID-19 Pandemic. Journal of Open Innovation: Technology, Market, and Complexity, 6(4), 104.

Richter, A. (2020). Locked-down digital work. International Journal of Information Management, 102157. 
Seetharaman, P. (2020). Business models shifts: Impact of Covid-19. International Journal of Information Management, 54, 102173.

Soto-Acosta, P. (2020). COVID-19 Pandemic: Shifting Digital Transformation to a High-Speed Gear. Information Systems Management, 1-7.

Venkatesh, V. (2000). Determinants of Perceived Ease of Use: Integrating Control, Intrinsic Motivation, and Emotion into the Technology Acceptance Model. Information Systems Research, 11(4), 342-365.

Von Briel, F., Davidsson, P., \& Recker, J. (2018). Digital technologies as external enablers of new venture creation in the IT hardware sector. Entrepreneurship Theory and Practice, 42(1), 47-69.

Warner, K. S., Wäger, M. (2019). Building dynamic capabilities for digital transformation: An ongoing process of strategic renewal. Long Range Plan. 52, 326-349.

Wollschlaeger, M., Sauter, T., \& Jasperneite, J. (2017). The future of industrial communication: Automation networks in the era of the internet of things and industry 4.0. IEEE industrial electronics magazine, 11(1), 17-27.

Yang, C., Huang, Q., Li, Z., Liu, K., \& Hu, F. (2017). Big Data and cloud computing: innovation opportunities and challenges. International Journal of Digital Earth, 10(1), 13-53. 